\title{
Effect of Transverse Static Magnetic Field on Droplets Transient and Inclusions Evolution During the Electroslag Remelting Process of GCr15 Ingots
}

\author{
Qiang $\mathrm{Li}^{1} \cdot$ Yun-Bo Zhong ${ }^{1} \cdot$ Chu-Xiong Sun ${ }^{1} \cdot$ Huai Wang ${ }^{1} \cdot$ Tian-Xiang Zheng $^{1} \cdot$ Wei-Li Ren $^{1} \cdot$ \\ Zhong-Ming Ren ${ }^{1}$
}

Received: 5 June 2018/Revised: 14 July 2018/Published online: 30 August 2018

(C) The Chinese Society for Metals and Springer-Verlag GmbH Germany, part of Springer Nature 2018

\begin{abstract}
The voltage was recorded to investigate the influence of the static magnetic field on droplet evolution during the magnetically controlled electroslag remelting (MC-ESR) process. MC-ESR experiments were carried out under different remelting current, and transverse static magnetic fields (TSMF) of $85 \mathrm{mT}, 130 \mathrm{mT}$ and $160 \mathrm{mT}$ were superimposed. Statistical work was performed to obtain the quantitative data of the droplets. The ASPEX Explorer was utilized to investigate the inclusions evolution of GCr15 ingots. The number of the droplets was 31 in 20 s during the traditional ESR process and reached 50 and 51 under the MC-ESR process with the TSMF of $85 \mathrm{mT}$ and $130 \mathrm{mT}$, respectively. When compared the traditional ESR process with the MC-ESR process, the inclusions amount reduced $67 \%$.
\end{abstract}

Keywords Electroslag remelting · Static magnetic field · Droplet transient · Inclusions evolution · Electromagnetic vibration effect

\section{Introduction}

Nonmetallic inclusions remained in the alloy steel ingots or high-temperature alloy ingots will destroy the matrix's continuity and increase the risk of inducing microcracks under stress, which will reduce the mechanical properties and the service life of the products [1]. Gutman et al. [2, 3] studied that the nonmetallic inclusions can be removed efficiently by electroslag remelting (ESR) process. The sounder structure can be obtained during the fabrication of ingots $[4,5]$. The ESR process has been widely used in many aspects such as functionally graded steel [6], highspeed steel [7] and metals with high reaction activity [8]. However, with the demands for huge ESR ingots, the ESR process still faces severe challenges. Low inclusion removal efficiency, oversized dendrites and macrosegregation are the three main factors have to be solved. These

Available online at http://link.springer.com/journal/40195

Yun-Bo Zhong

yunboz@staff.shu.edu.cn

1 State Key Laboratory of Advanced Special Steels, Shanghai University, Shanghai 200072, China flaws are mainly attributed to the low solidification rate [9]. Therefore, ideal alternative technologies are emergently required to produce huge steel ingots with high performance.

The application of an alternative magnetic field has attracted much attention during the last decades. It efficiently refines the solidified structure of alloy with the help of the induced Lorenz force in the molten alloy $[10,11]$. Electromagnetic field has been considered as the most promising dominant method to control the heat, mass transfer and solidification process [12, 13]. Langenberg [14] described that an alternating magnetic field would influence the solidification process and refine the microstructure in the continuous casting production of alloy. Moreover, the rotating magnetic field has acted as an important way to promote the dendrite to turn to equiaxed grain during the solidification process of alloys, especially, during the casting of steel or aluminum alloys $[15,16]$. Due to the strong shielding effect in the thick copper pipe which is used in the ESR furnace, it is not easy to introduce an alternative magnetic field into the ESR process. Traditionally, in the ESR process, $50 \mathrm{~Hz}$ alternating current is often used to melt the consumable electrode and slag; then, Lorenz force could be induced if a TSMF was introduced. 
Of importance here, there is no shielding effect generated in the copper pipe for the TSMF.

In the present paper, a novel concept named magnetically controlled electroslag remelting (MC-ESR) process has been proposed (Fig. 1a). Compared to the traditional ESR process, an alternating current with $50 \mathrm{~Hz}$ and a transverse static magnetic field (TSMF) have been applied during the ESR process. The induced Lorenz force in the molten slag pool, the metallic melting pool and the droplets influence the droplets transient and inclusions evolution remarkably. A physical mechanism is established to describe this process.

\section{Experimental}

The GCr15 $\Phi 25 \mathrm{~mm} \times 700 \mathrm{~mm}$ consumable electrodes (the chemical compositions are listed in Table 1) were remelted by using a micro-ESR system with a TSMF as shown in Fig. 1a. The TSMF was provided by two groups of the NdFeB magnets. Each block of the NdFeB magnet had the size of $80 \mathrm{~mm} \times 40 \mathrm{~mm} \times 10 \mathrm{~mm}$. By changing the number of the $\mathrm{NdFeB}$ magnets, the magnetic flux density in the air gap between the two grouped magnets could be tuned from $0 \mathrm{mT}$ to $160 \mathrm{mT}$. The mold was made of copper and stainless steel. The inner diameter and height of the mold were $50 \mathrm{~mm}$ and $130 \mathrm{~mm}$, respectively. The voltage between the consumable electrode and the bottom electrode was recorded by the device of ADVANTECH USB-4711A with a collection frequency of $1 \times 10^{6} \mathrm{~Hz}$.

A circular iron base plate was fixed on the bottom electrode to protect the bottom copper electrode plate. The slag was made of $20 \% \mathrm{CaO}, 20 \% \mathrm{Al}_{2} \mathrm{O}_{3}$ and $60 \% \mathrm{CaF}_{2}$. The $\mathrm{AC}$ intensities in a range from $400 \mathrm{~A}$ to $800 \mathrm{~A}$ with a frequency of $50 \mathrm{~Hz}$ were introduced into the MC-ESR

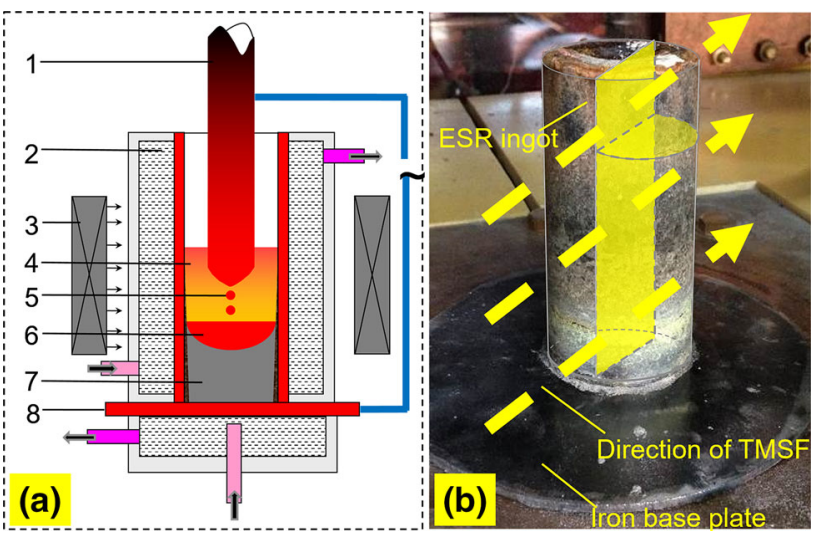

Fig. 1 a Schematic view of the ESR process under a static magnetic field (1-consumable electrode, 2-water-cool mold, 3-permanent magnets, 4-slag pool, 5-droplet, 6-metal pool, 7-ingot, 8bottom cooper electrode), b MC-ESR GCr15 ingot
Table 1 Chemical composition of the consumable electrode used in experiments (wt\%)

\begin{tabular}{lllllll}
\hline $\mathrm{C}$ & $\mathrm{Si}$ & $\mathrm{Mn}$ & $\mathrm{S}$ & $\mathrm{P}$ & $\mathrm{Cr}$ & $\mathrm{Al}$ \\
\hline 0.980 & 0.025 & 0.367 & 0.011 & 0.032 & 1.39 & 0.023 \\
\hline
\end{tabular}

process according to the previous research [17]. Two grouped magnets were located at the outside of the mold. Combined with the four different magnetic flux densities and 400 A remelting current, the MC-ESR experiments were carried out in the groups as listed in Table 2. Powder slag was melt by the Joule heat. Then, the liquid slag was used for melting the consumable electrode and offered a controlled molten metal pool. Finally, the ESR ingots with the diameter of $50 \mathrm{~mm}$ and height of $100 \mathrm{~mm}$ could be obtained.

ESR ingots were cut into two parts along the axial direction, and one of them was cut along the radial direction as shown in Fig. 1b. For the cross section profile analysis, the 10-mm-thick one was sampled and each sample was carefully grinded and polished. In detection analysis, ASPEX Explorer (manufactured by FEI) was used to observe and obtain the quantitative data of the nonmetallic inclusions. The amounts of phosphorus element were measured by PMI-MASTER PRO portable spectrometer.

\section{Results and Discussion}

\subsection{Droplets Transient Under Different Current Intensities}

In order to understand how the TSMF influences the droplet transient during the MC-ESR process, it is necessary to do experiments without the TSMF for comparison. The experiments were carried out under the different remelting current intensities $(400 \mathrm{~A}, 500 \mathrm{~A}, 600 \mathrm{~A}, 700 \mathrm{~A}$ and $800 \mathrm{~A})$ without an external magnetic field. The continuous data of the voltage were recorded during the ESR process. The results showed a difference between the ESR process and the power current, which is shown in Fig. 2. Lots of peak values can be found. The peak value appeared at the moment when the droplet was separated from the tip of the consumable electrode.

To better explain the peak value, visualization of the droplet transient process was conducted as shown in Fig. 3a. The resistance between the consumable electrode tip and the melting pool was changed as the droplet appeared, reached its critical size and fell from the consumable electrode tip. The voltage data would change with 
Table 2 Remelting current and intensities of the TSMF conditions in experiments
Remelting current intensities (A)

Intensities of the external TSMF (mT)

$400,500,600,700$ and 800

$0,85,130$ and 160

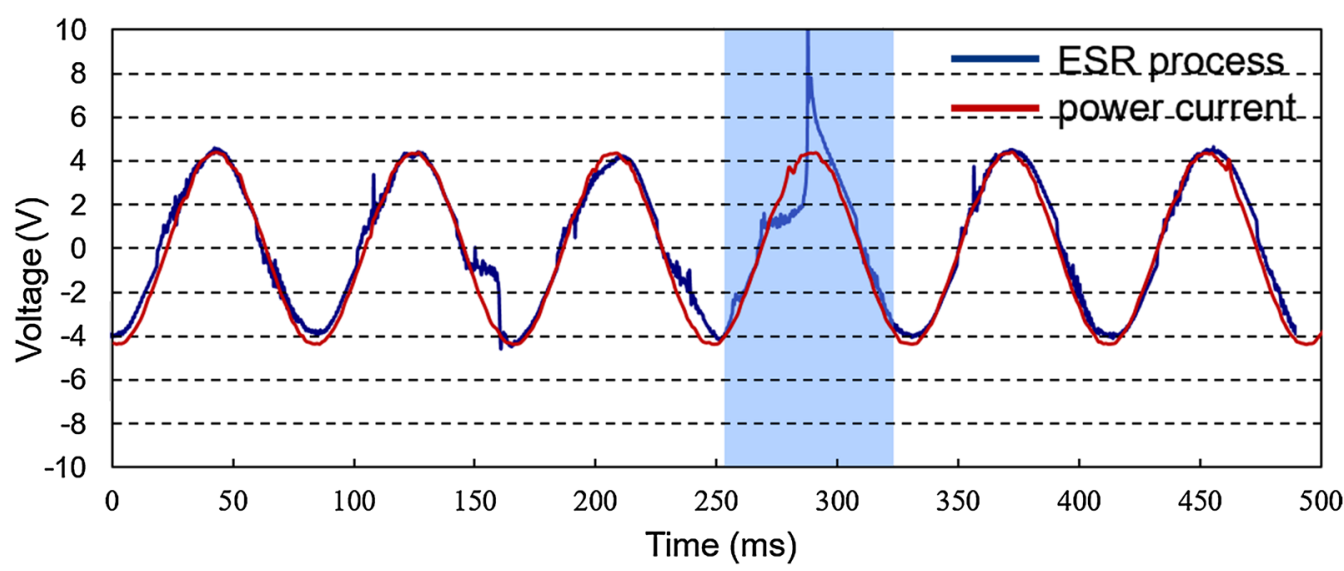

Fig. 2 Peak value of the voltage data during the ESR process
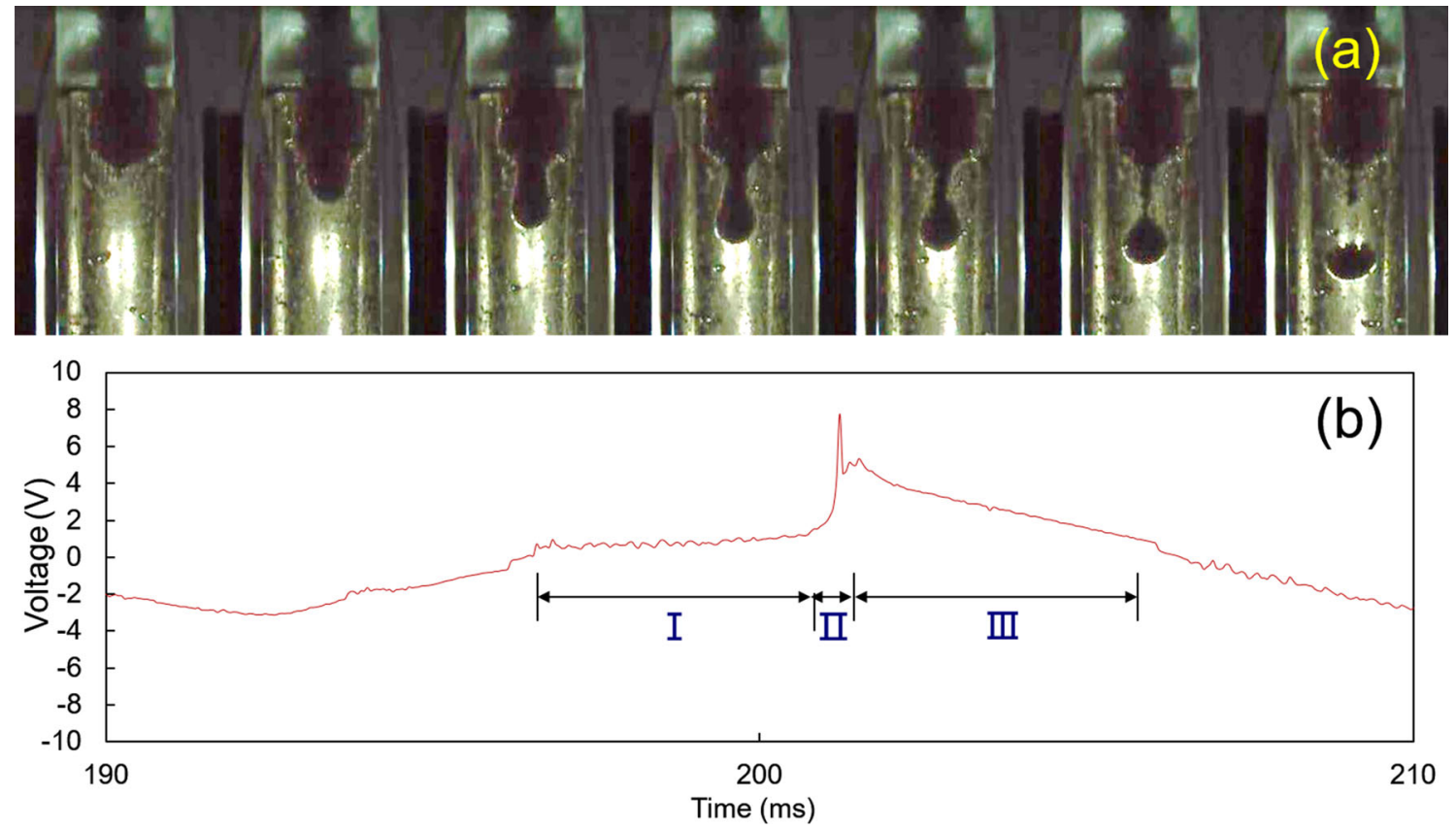

Fig. 3 a Visualization of the droplet transient, b peak value of the voltage during the ESR process

the change in resistance (Fig. 3b). Statistical work has been done by analyzing the voltage data to evaluate the amount of the droplets under different remelting current intensities as shown in Fig. 4. With the increase in the current intensity, the Joule heat produced by the molten slag increases. As a result, the number of the droplets increases.

\subsection{Droplets Transient Under Different TSMF Intensities}

The experiments were carried out under different intensities $(0 \mathrm{mT}, 85 \mathrm{mT}, 130 \mathrm{mT}$ and $160 \mathrm{mT})$ of the external TSMF when the remelting current was $400 \mathrm{~A}$. Voltage data in $20 \mathrm{~s}$ were collected during the MC-ESR process, which is shown in Fig. 5.

For the traditional ESR process (Fig. 5a), the main feature is the high superheat of metal due to the high 


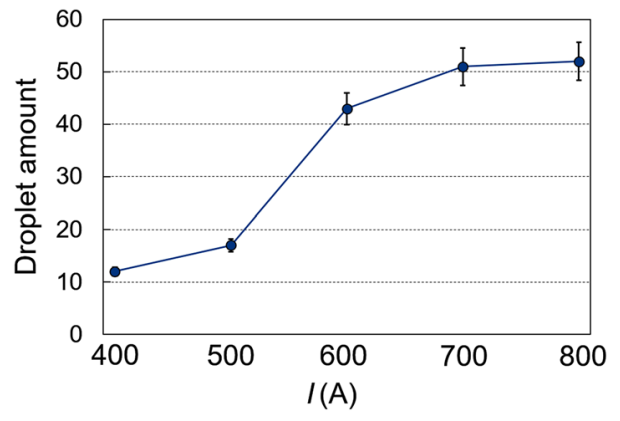

Fig. 4 Number of the droplets under different remelting current intensities
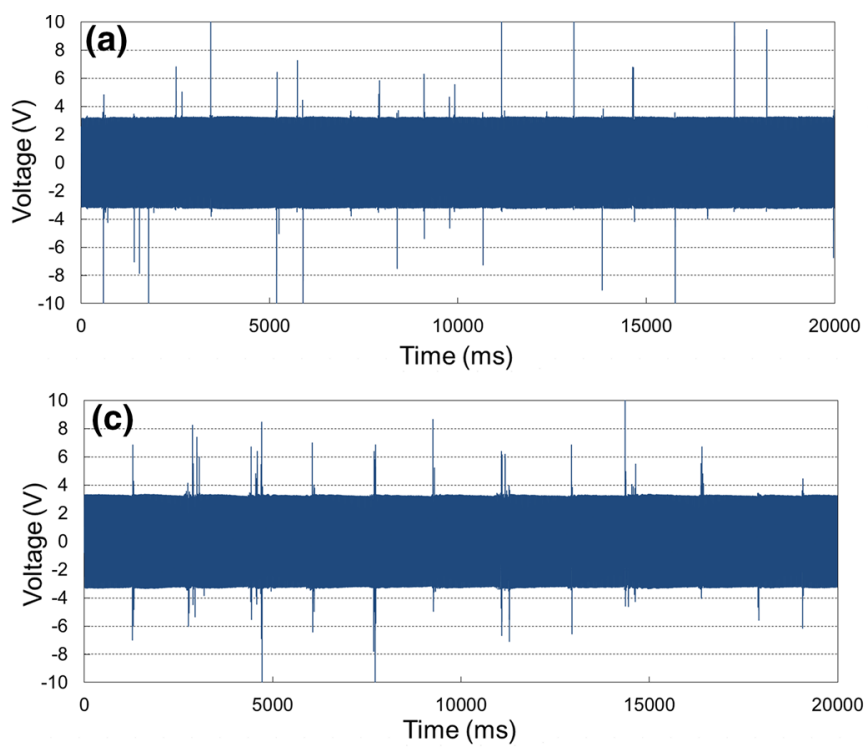

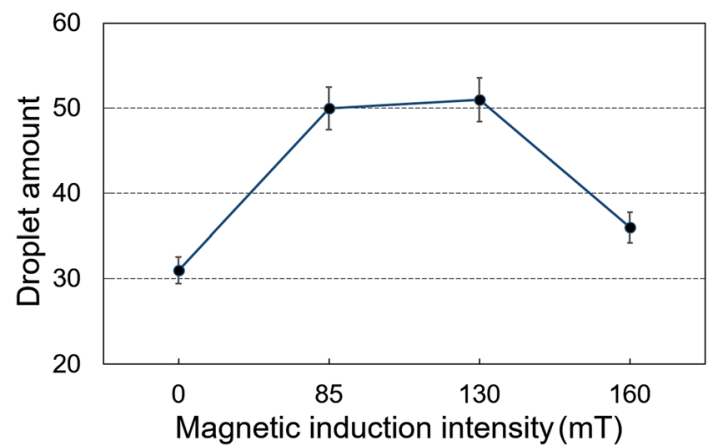

Fig. 6 Number of droplets under different intensities of TSMF
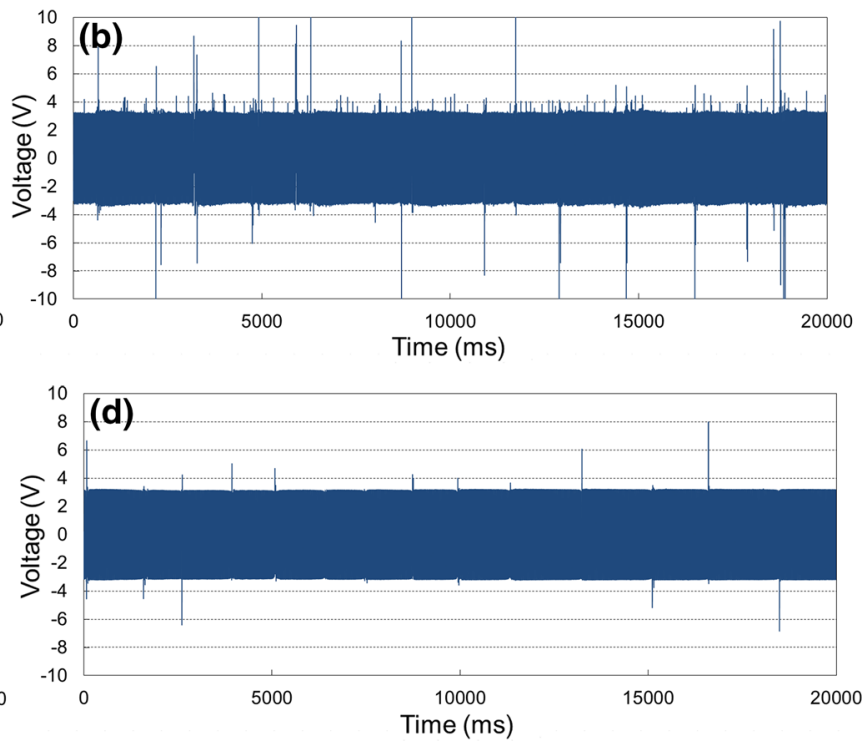

Fig. 5 Voltage data in $20 \mathrm{~s}$ during the MC-ESR process: a $0 \mathrm{mT}$, b $85 \mathrm{mT}$, c $130 \mathrm{mT}$, d $160 \mathrm{mT}$

temperature of the molten slag. The temperature of the molten slag is usually $423-473 \mathrm{~K}$ higher than that in metallic melting pool [18], which resulting in a relatively low cooling speed during the solidification process [19]. The application of a TSMF caused significant positive changes to the droplets transient during the ESR process (Fig. 5b-d). After the application of $85 \mathrm{mT}$ and $130 \mathrm{mT}$ TSMF, the counts of the voltage peak are obviously increased (Fig. 5b, c). When the intensities of TSMF reached $160 \mathrm{mT}$, the frequency of the occurrence of voltage peak did not increase.

Statistical results of the number of droplets under different intensities of TSMF are shown in Fig. 6. During the traditional ESR process, 31 droplets were recorded in $20 \mathrm{~s}$. The number reached 50 and 51 when the TSMF were $85 \mathrm{mT}$ and $130 \mathrm{mT}$, respectively, under the MC-ESR process. When the intensities of TSMF reached $160 \mathrm{mT}, 36$ droplets were recorded in $20 \mathrm{~s}$. The result showed that the number of droplets increased $66.7 \%$ when the suitable TSMF was applied, and the remelting current kept the same.

The effort that increased the number of the droplets was stimulated by the effectiveness of the electromagnetic vibration caused by the interaction between the alternating current and the TSMF. The above phenomenon guides us a bright direction that it is possible to produce the ESR ingots quickly by a static magnetic field and reduce the power supply.

\subsection{Element and Inclusion Analysis}

Figure 7 summarizes the influence of TSMF on the phosphorus (P) content in the remelted ingot under different intensities. This indicates that, in the absence of TSMF and with the increase in the current, the dephosphorization effect was inhibited because of the exothermic reaction which leads to the rising of the temperature in the slag pool. In the case of $85 \mathrm{mT}$ TSMF, the phosphorus content is further reduced by $10 \%$. When the intensity of TSMF 


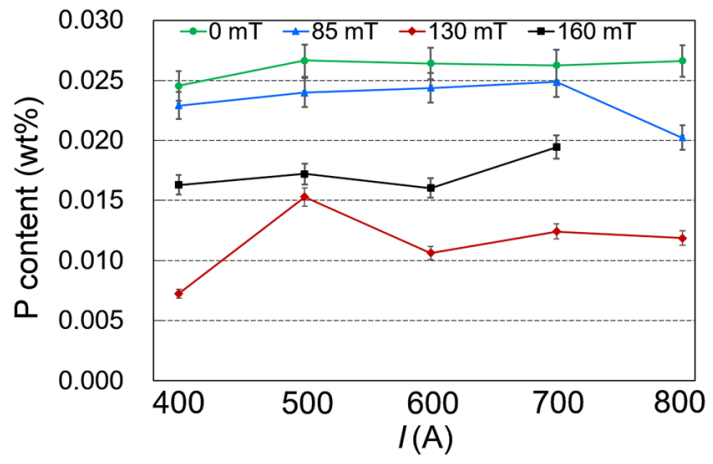

Fig. 7 Influence of TSMF on phosphorus (P) content of MC-ESR ingot with different intensities of AC

increases to $130 \mathrm{mT}$, the phosphorus content reaches the minimum value $72.6 \mathrm{ppm}$ with the current of $400 \mathrm{~A}$.

The influences of TSMF on the number of inclusions of remelted ingots under different intensities of the TSMF are summarized in Fig. 8. It is found that the number of inclusions is 733 in a collected area of $8.405 \mathrm{~mm}^{2}$ on the traditional ESR ingot. When it comes to the cases of $130 \mathrm{mT}$ and $160 \mathrm{mT}$ TSMFs, the numbers of inclusions are further reduced to 241 and 301, respectively. Therefore, it can be concluded that the TSMF is in favor of the elimination of the phosphorus element and the decrease in the number of inclusions.

During the original ESR process, consumable electrode was melted by the Joule heat. Melted metal droplets fell into the metallic melting pool vertically (Fig. 9a). As a result, a deep melted pool was formed. By using MC-ESR process, the alternating Lorentz force was induced when imposing a TSMF. The alternating Lorentz force will change its direction frequently as the $50 \mathrm{~Hz}$ alternating current. In the first half cycle of the alternating current, the Lorentz force points left. When the current changes to the other half cycle, the Lorentz force points right (Fig. 9b); consequently, the electromagnetic oscillation affects the direction of initial velocity and the volume of melting

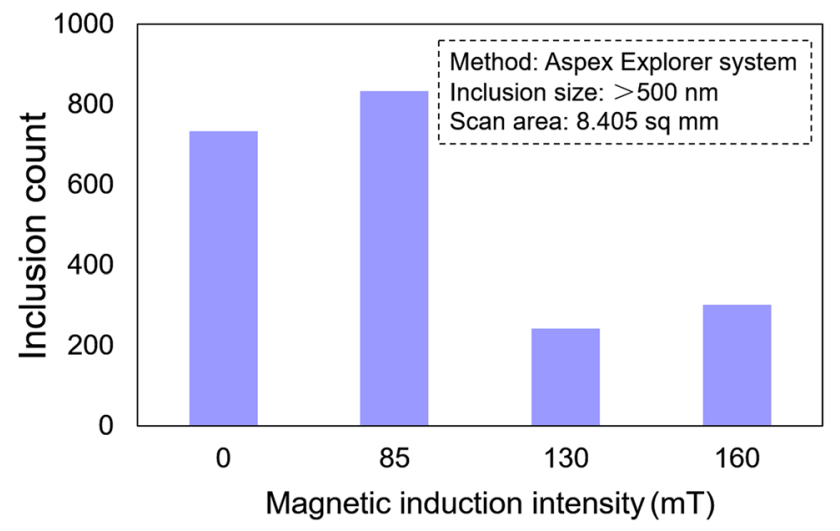

Fig. 8 Influence of TSMF on inclusion count of MC-ESR ingot
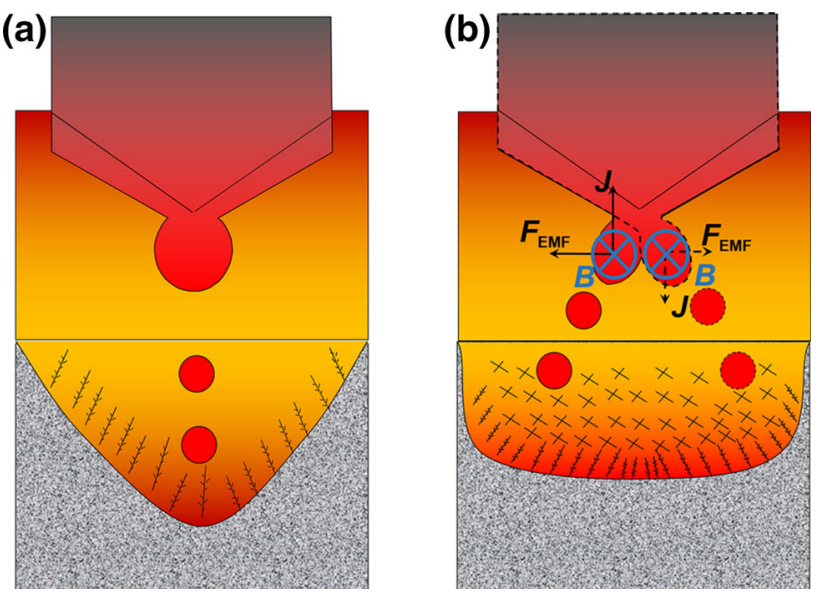

Fig. 9 Schematic view of MC-ESR

droplets. The droplets would fell into the melted pool in a smaller shape dispersively. Thus, a shallower melt pool was formed, and the metallic liquid-solid interface was much more flat. As a result, the temperature field in the melted pool became more uniform. A smaller shape of the melting droplets and a shallower melt pool could make it easier for the inclusions to move to the melting slag pool and be removed by the slag. In the ordinary ESR process, the dephosphorization effect was inhibited because of the exothermic reaction which leads to the rising of the temperature in the slag pool. By using MC-ESR process, the temperature field in the melted pool became more uniform and caused significant positive changes to the elimination of the phosphorus element.

\section{Conclusions}

1. A process of the MC-ESR is proposed. Recording the voltage data is a credible method to study the droplets transient during the MC-ESR process.

2. The number of droplets increases without adding the power supply with TSMF of $130 \mathrm{mT}$ in the MC-ESR process. The phosphorus content and number of inclusions decrease under the effect of TSMF.

3. The electromagnetic vibration effect improves the refinement capacity of ESR process.

Acknowledgements The authors gratefully acknowledge the financial support of the National Key Research and Development Program of China (No. 2016YFB0300401), the National Natural Science Foundation of China (Nos. U1732276 and 51704193), the General Financial Grant from the China Postdoctoral Science Foundation (No. 2017M621431), the Science and Technology Commission of Shanghai Municipality (No. 15520711000) and Independent Research and Development Project of State Key of Advanced Special Steel, Shanghai University (SKLASS2015-Z021, SELF-2014-02). 


\section{References}

[1] A. Choudh, ISIJ Int. 32, 563 (1992)

[2] E.R. Gutman, V.A. Durynin, GYu. Kalinin, Russ. Metall. 2009, 655 (2009)

[3] J. Reitz, B. Wietbrock, S. Richter, Adv. Eng. Mater. 13, 395 (2011)

[4] Y.W. Dong, Z.H. Jiang, H. Liu, R. Chen, Z.W. Song, ISIJ Int. 52, $2226(2012)$

[5] H. Halfa, Steel Res. Int. 84, 495 (2013)

[6] H. Salavati, Y. Alizadeh, F. Berto, Acta Metall. Sin. (Engl. Lett.) 28, 164 (2015)

[7] Y.L. Ji, W. Zhang, X.Y. Chen, J.G. Li, Acta Metall. Sin. (Engl. Lett.) 29, 382 (2016)

[8] J. Fu, Acta Metall. Sin. 15, 526 (1979) (in Chinese)

[9] B. Podgornik, V. Leskovšek, M. Godec, B. Senčič, Mater. Sci. Eng. A 599, 81 (2014)
[10] X. Li, Z.M. Ren, H. Wang, Acta Metall. Sin. 40, 40 (2004) (in Chinese)

[11] P.A. Nikrityuk, K. Eckert, R. Grundmann, Int. J. Heat Mass Transf. 49, 1501 (2006)

[12] M. Murgaš, A.S. Chaus, ISIJ Int. 40, 980 (2000)

[13] M. Murgaš, A.S. Chaus, Fiz. Khim. Obrab. Mater. 2, 99 (1998)

[14] F.C. Langenberg, G. Pestel, C.R. Honeycutt, TMS-AIME 221, 895 (1961)

[15] W.C. Johnston, G.R. Kotler, W.A. Tiller, TMS-AIME 227, 890 (1963)

[16] D. Chen, C.L. Chen, X.L. Wen, Acta Metall. Sin. 44, 609 (2008) (in Chinese)

[17] M.L. Feng, Y.B. Zhong, Q.F. Wu, J. Iron Steel Res. Int. 19, 363 (2012)

[18] B.E. Paton, B.I. Medovar, G.A. Bojko, Electroslag Casting, vol. 192 (Naukova Dumka, Kiev, 1980)

[19] A. Mitchell, B. Hernandez-Morales, Metall. Trans. B 21, 723 (1990) 